\title{
Development of Social Media GIS to Support Information Utilization from Normal Times to Disaster Outbreak Times
}

\author{
Kayoko YAMAMOTO \\ Associate Professor, \\ Graduate School of Information Systems, \\ University of Electro-Communications \\ Tokyo, Japan
}

\author{
Shun FUJITA \\ Graduate School Student, \\ Graduate School of Information Systems, \\ University of Electro-Communications \\ Tokyo, Japan
}

\begin{abstract}
The present study aims to design, develop, operate and evaluate a social media GIS (Geographical Information Systems) specially tailored to mash-up the information that local residents and governments provide to support information utilization from normal times to disaster outbreak times in order to promote disaster reduction. The conclusions of the present study are summarized in the following three points. (1) Social media GIS, an information system which integrates a Web-GIS, an SNS and Twitter in addition to an information classification function, a button function and a ranking function into a single system, was developed. This made it propose an information utilization system based on the assumption of disaster outbreak times when information overload happens as well as normal times. (2) The social media GIS was operated for fifty local residents who are more than 18 years old for ten weeks in Mitaka City of Tokyo metropolis. Although about $32 \%$ of the users were in their forties, about $30 \%$ were aged fifties, and more than $10 \%$ of the users were in their twenties, thirties and sixties or more. (3) The access survey showed that 260 pieces of disaster information were distributed throughout the whole city of Mitaka. Among the disaster information, danger-related information occupied $\mathbf{2 0 \%}$, safety-related information occupied $68 \%$, and other information occupied $12 \%$.
\end{abstract}

Keywords-Social Media GIS; Web-GIS; SNS; Twitter; Disaster Information; Disaster Reduction; Support for Information Utilization

\section{INTRODUCTION}

According to the White Paper on Disaster Management (2012) [1], measures for disaster prevention and reduction of the effects of natural disasters in Japan include "self-help", "mutual help (cooperation)", and "public help (rescue and assistance by public bodies)". "Self-help" refers to local residents, businesses, and other entities protecting themselves from disaster; "mutual help (cooperation)" refers to local communities helping each other; and "public help" refers to measures by government bodies such as national and local governments. Further, the most fundamental form of help was said to be self-help, which involves measures taken by individuals. Nowadays, anybody, anywhere, anytime can use an information system to easily send, receive, and share information, and through the effective use of information systems, disaster information possessed by local residents can be accumulated and shared.
Additionally, the Science Council of Japan (2008) [2] divided "local knowledge" into "expert knowledge" based on scientific knowledge, and "experience-based knowledge" produced by the experiences of local residents, and indicated its importance. Concerning "local knowledge" that is the "experience-based knowledge" of local residents, and exists as "tacit knowledge" that is not visualized if it is not communicated to others, as a measure for disaster prevention and reduction, it is essential for the "experience-based knowledge" to be transformed into "explicit knowledge" which is of a form that can be accumulated, organized, utilized, and made publicly available through the use of information systems, and to have local related entities accumulate the knowledge together. Moreover, Committee for Policy Planning on Disaster Management - Final Report by the Central Disaster Management Council (2012) [3] particularly specified the importance of the roles of GIS (Geographic Information Systems) and social media in the collection and transmission of disaster information.

Regarding the examples of disaster management in other parts of the world, Greene (2002) [4] proposed five stages of disaster - identification and planning, mitigation, preparedness, response, and recovery -, and shows how GIS processes can be incorporated into each. Vivacqua et al. (2012) [5] considered the four phases of emergency management which are related in a cyclic fashion: mitigation, preparedness, response, and recovery. They discussed possibilities for the introduction of collective knowledge in emergency response systems. Mansourian et al. (2006) [6] addressed the role of Spatial Data Infrastructure (SDI) as a framework for the development of a web-based system to facilitate disaster management with emphasis on the response phase in Iran. Neuvel et al. (2012) [7] proposed the network-centric concept of spatial decision support for risk and emergency management in Netherland. In the present study, firstly, with reference to the White Paper on Disaster Management (2012) [8], Committee for Policy Planning on Disaster Management - Final Report (2012) [3], and Vivacqua et al. (2012) [5], disaster risk management is divided into three stages - normal times, disaster outbreak times, and times of recovery and reconstruction -.

In Japan, as a disaster countermeasure, local governments provide information to local residents in the form of disaster 
prevention maps and hazard maps which show local hazardous places, evacuation sites and so on. However, this information is mainly published as maps that are in paper form or in PDF format on the website. Therefore, it is difficult to update the information on disaster prevention maps and hazard maps in real time, and these forms of information are not very suited to being shared during a disaster outbreak. Further, so that information can be efficiently accumulated and shared during a disaster outbreak, it is desirable that information systems which people are accustomed to using in normal times can be used as is during disasters. However, when a disaster occurs, a situation where the amount of submitted information increases, and there is an excessive amount of information can be expected; therefore, it is necessary for systems to automatically classify submitted information.

Against the above-mentioned background, the present study aims to design and develop a social media GIS for reducing the effects of natural disasters in normal times through to disaster outbreak times. This is achieved by designing and developing a social media GIS that integrates a Web-GIS with an SNS and Twitter, and includes a function for classifying submitted information. The social media GIS enables disaster information provided by local residents and governments to be mashed up on a GIS base map, and for the information to be classified and provided to support the utilization of the information by local residents. Further, the present study also aims to operate the social media GIS and evaluate the operation. During normal times when there is no disaster, disaster information is collected via the SNS, and local disaster information is accumulated. Through this, the system aims to improve the disaster prevention awareness of local residents. Further, during disaster outbreaks when there is an excess of information, if a communications environment (electricity, internet, information terminals, etc.) can be secured, the system aims to support evacuation activities by automatically classifying disaster information, promptly displaying it on the digital map of the Web-GIS, and ensuring its noticeability. Through having people use the system routinely and get used to it in normal times in this manner, the possibility that the system can be effectively used with no problem as a means for reducing the effects of natural disasters even in tense situations during disaster outbreaks can be anticipated.

\section{RELATED WORK}

The aim of the present study is to develop a social media GIS that supports the utilization of disaster information and acts as a measure for reducing the effects of natural disasters from normal times through to disaster outbreak times. Therefore, prior research in fields related to the present study [9]-[26] can be classified into the following three areas: (1) Research relating to system development which utilizes GIS; (2) Research relating to the development of social media GIS; and (3) Research relating to proposals for systems that classify submitted information.

As representative examples of research in recent years, in the research area of (1), as a measure to reduce the effects of natural disasters during normal times, Murakami et al. (2009) [9] developed a system that supports disaster prevention workshops by using a GIS. In the research area of (2), Okuma et al. (2013) [10] developed a social media GIS that integrated a Web-GIS, an SNS, and Twitter, and demonstrated improvement of local residents' disaster prevention awareness through the accumulation of disaster information, as a measure for reducing the effects of natural disasters during normal times. Further, Murakoshi et al. (2014) [11] integrated a function for classifying submitted information into the social media GIS of Okuma et al. (2013) [10], and developed a system effective as a measure for reducing the effects of natural disasters from normal times through to disaster outbreak times. Yamanaka et al. (2010) [12] proposed a support system for situation assessment which utilized text data with spatio-temporal information and was designed for use by managers of facilities. They conducted an experiment in a large-scale park which involved a hypothetical disaster outbreak, summarized submitted text data information, and displayed the congested local situation on a web map using icons as messages. Further, Moriya et al. (2009) [13] proposed a system in which text data relating to local information in blogs was used to display the local situation (such as image, impression, and atmosphere of a place) on a web map by using circular depictions.

In the above-mentioned prior research in fields related to the present study, measures for reducing the effects of natural disasters during normal times include development of a system which uses GIS to support disaster prevention workshops, and development of a social media GIS which accumulates disaster information. Government measures include the Japanese Ministry of Land, Infrastructure, Transport and Tourism's Hazard Map Portal Site ${ }^{(1)}$, and disaster prevention maps and hazard maps provided by local governments. Further, there is research which proposed a system which utilizes text data to display the local situation on a web map using icons and circles which was demonstrated as being useful. However, except for in research by Murakoshi et al. (2014) [11], up to now, there has not been development of a system designed for use from normal times through to disaster outbreak times which, in order to reduce the effects of natural disasters on a sustained and continuous basis throughout such periods, supports utilization of disaster information possessed by local residents by automatically classifying disaster information provided by local residents and promptly displaying it, and providing it on a GIS base map together with disaster information provided by governments with which it is mashed up. Therefore, the present study is based on the research results of Murakoshi et al. (2014) [11] in particular, and is unique in that it uniquely designs and develops a social media GIS aimed at realizing the features outlined above. Further, the present study is unique in that it operates the social media GIS and conduct an evaluation of the operation.

\section{RESEARCH OUTLINE AND METHOD}

In the present study, research is conducted according to the following outline and method. Firstly, a social media GIS which specializes in the aim of the present study is uniquely designed (Section IV) and developed (Section V). Next, anticipating users are the general public who are more than 18 years, an operation test and operation of the social Media GIS (Section VI) are conducted. Further, the system is evaluated and measures for improving use of the system are identified 
(Section VII). Anticipating that each user will use the system for about a month, an operation test and an evaluation of operation test are conducted, and then actual operation is conducted. In addition, access is analyzed using log data during the period of actual operation, and submitted information is analyzed. Based on the results of these steps, the system is evaluated, and measures for using the system in order to more effectively support people utilizing disaster information are identified. Mitaka City of Tokyo metropolis was selected as the region for operation. This is because Mitaka City is the advanced local government of regional computerization in Japan, and cooperated with the present study.

\section{DESIGN OF THE SYSTEM}

\section{A. System Features}

In the present study, a social media GIS effective in supporting the utilization of disaster information has a design in which a function capable of classifying and displaying submitted information according to location information and content is included in a system which combines three web applications - a Web-GIS, an SNS and Twitter, as shown in Fig. 1. The system has a structure in which the Web-GIS and the submitted information classification function are installed in the SNS. Use of the SNS and twitter enables provision of information from local residents, and enables local information concerning disasters possessed by local residents as tacit knowledge to be converted to explicit knowledge, and accumulated and shared among users. During normal times, through the SNS and twitter, local residents who are the users of the social media GIS will submit information such as information concerning dangerous and safe places in disaster outbreak times which is not noted in detail on disaster prevention maps or hazard maps produced by the government. In disaster outbreak times, through the SNS and Twitter, the local residents will submit similar information, after ensuring their own safety. Further, disaster information provided by the government in normal times, such as that concerning overall degree of danger and facilities that provide support in disaster outbreak times, will be accumulated in advance, and disaster information provided by the government during disasters will also be collected and accumulated.

The above-mentioned disaster information submitted by local residents and disaster information provided by the government will be saved in a database, and the former information will be classified according to location information and content. Together with the disaster information from the government, the classified information will be integrated into the Web-GIS, mashed up on a digital map, and visualized. Therefore, on the Web-GIS digital map, even in situations where a disaster has occurred and there is an excess of information, high noticeability of all submitted information can be maintained, and on the digital map, users can efficiently accumulate and share disaster information which includes location information among themselves.

Based on the above, the usefulness of the present system lies in the fact that it can ease the restrictions mentioned in the following three points:

1) Bidirectionality of information transmission: In this system, information submission and viewing functions are installed in the SNS. This allows all users to submit and view information anytime from anywhere regardless of whether it is during normal times or disaster outbreak times.

2) Mitigation of burden of obtaining information: In this system, the system automatically classifies submitted information and displays it on the digital map of the Web-GIS. Therefore information can be processed in real time, and users can easily determine the riskiness and safety of places that is conveyed by the information. Further, the situation where a user does not know their own present location outside has been anticipated, and the system obtains location information and displays facilities that provide support during disasters in the neighborhood where the user is located, and also displays information submitted concerning the neighborhood where the user is located. Therefore the system can reduce the burden experienced when obtaining disaster information.

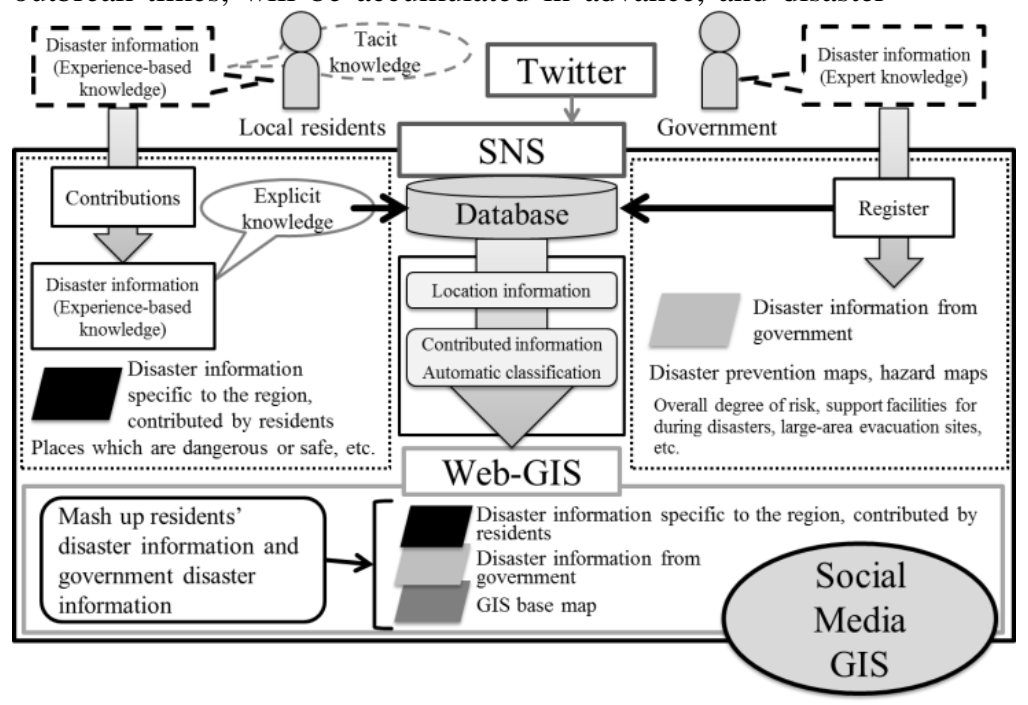

Fig. 1. System design of social Media GIS 
3) Mitigation of spatial and temporal restrictions: The information terminals that this system is designed for use with are PCs and mobile information terminals. Concerning the latter, the system is designed for use with smartphones and tablet terminals, whose use has rapidly spread in recent years. Both these types of mobile information terminals have touch panels with large screens, making them easy to use when dealing with digital maps, and both types allow connection to the internet from anywhere via mobile phone data communication networks. Anticipating the situation of users using the system outdoors as well during both normal times and disaster outbreak times, a system compatible with both PCs and mobile information terminals has been designed and developed. Thanks to this, the system can be used anytime, regardless of whether the user is indoors or outdoors.

\section{B. System Design}

\section{1) System configuration}

The social media GIS of the present study is formed using three servers - a web server, a database server, and a GIS server. The web server mainly performs processing related to the SNS, and accesses the GIS server and the database server to integrate each of the functions. The SNS is operated using JavaScript and PHP, and the database server is managed using MySQL, and stores disaster information submitted by local residents which is collected through the SNS and Twitter, and disaster information from the government. For the web server and the database server, the rental server of the information infrastructure center of the organization to which the authors belong was used. For the GIS server, as the OS, Microsoft Corporation's Windows Server 2008 was used, and as the GIS server software, Esri's ArcGIS Server 10.0 was used.

\section{2) $W e b-G I S$}

In the present study, for the Web-GIS, Esri's ArcGIS Server 10.0 was used, and for the GIS base map of the WebGIS, the SHAPE version (Rel.8) of Shobunsha Publications, Inc.'s MAPPLE10000, which is part of their MAPPLE digital map data and includes detailed road system data, was used. As the map that was superimposed with this digital map data, the user interface of Google Maps was used. Among the options provided by Esri that are ArcGIS Server 10.0 API targets, the Google Maps user interface is the one that has been used the most in earlier studies in fields related to the present study. Concerning the superimposition of MAPPLE10000 (SHAPE version) and Google Maps, Google Maps employs the new geodetic system coordinates, while MAPPLE10000 conforms to the former geodetic system coordinates; therefore, ArcTky2Jgd, which is provided by Esri as product support, was used to convert the MAPPLE10000 geodetic system coordinates to the new coordinates. Furthermore, editing was performed using ArcMap 10.0 such that disaster information provided by Mitaka City and the Metropolis of Tokyo, the regions for operation, and information peculiar to each place could be input.

Since the object of the present study is disaster information, users can use the Web-GIS to refer to a detailed road system that includes small streets that is output from MAPPLE10000, and by doing so they can accurately check locations related to submitted information, and in particular, precisely display disaster information related to the risk and safety of evacuation routes in disaster outbreak times. Further, the system has been set such that when the PC interface for users is used, the digital map can be viewed using full screen display. Thanks to this, users can get a general view of submitted information over a wide range, and enlarge the digital map to check information in detail.

\section{3) $S N S$}

In the present study, an SNS was firstly selected as the social media for integration with the Web-GIS. The SNS was uniquely designed and developed to suit the objectives of the present study. An SNS was chosen because if an SNS is used, the system can be uniquely designed and developed to suit the objectives of use, and detailed system configuration can be performed to suit regional characteristics of the regions in which the system is to be operated. In this system, community functions limiting topics and users were not included, and functions related to user personal data registration and profile publication, submission and viewing of information and image, and commenting were uniquely designed to suit to the objectives of the present study. Since the object of this system is disaster information, for which reliability is regarded as important, the system has been designed such that it requires users to register, and each individual user can be identified by either their real name or an assumed user name. Therefore, the system is designed such that an environment in which it is difficult to make inappropriate statements or behave inappropriately has been prepared in advance, and the reliability of submitted information and comments can be improved.

Further, a button function and ranking function have been included in the SNS. Concerning the button function, it is used when users view disaster information which has already been submitted, and allows users to easily express that they have the same information. Further, a ranking function was added to the button function, and on the disaster information ranking page of the user screen, the five information items for which the most amount of users have the same information are displayed in descending order.

\section{4) Twitter}

The present study employs a system design which allows realization of long-term operation by preventing reduction in the number of active users, and allows users to submit information anytime using mobile information terminals regardless of whether they are indoors or outdoors. Therefore, Twitter was secondly selected from among the various forms of social media, and was mashed up with the SNS which was uniquely developed, as mentioned in the previous section. Of the various forms of social media, Twitter has the easiest information submission method, and many tweets per day can be expected, so it is essential for realizing long-term operation of the system. The system is designed such that when users submit information from Twitter, they tag the information with the hashtag \#mtkgis and with location information which employs a GPS. 
5) Function for classifying submitted information

Anticipating situations where a lot of information is submitted when a disaster has occurred and there is an excess of information, a function which automatically classifies and organizes submitted information was set up and installed in the SNS. Similarly to what is described in Moriya et al. (2009) [13] in Section II, a method in which words related to local information are obtained from submitted information, and the local situation and that location are displayed on the digital map via a circular illustration is employed. In the present study, submitted information is classified into two categories according to whether it relates to either danger or safety. The system automatically classifies submitted information by searching submitted content using multiple character string searches which employ regular expressions. Specifically, when the words "danger" or "dangerous" are included in submitted information it is classified as information relating to danger, and when the word "safe" is included in submitted information it is classified as information relating to safety. Submitted information is classified right after being submitted and can be displayed on the Web-GIS digital map immediately.

Concerning this point, so that the system can accurately automatically classify and display submitted information as information related to either danger or safety, rules for making submissions which include specific illustrative examples are presented in advance on the initial page of the system and in the instructions for use of the system which are distributed to all users, so that users do not use vague expressions. Through this, due to having the users submit information according to the above-mentioned rules during normal times, even in disaster outbreak times it can be anticipated that users will continue to submit information in a similar manner; therefore, the probability that the system can appropriately classify submitted information can be increased.

As outlined above, when submitted information that has been classified is registered in the database, flags are added to it; therefore, the system is designed such that fields are created in advance in the database and flags can be stored in the database. When illustration is made using the Web-GIS, illustration is made using semitransparent circles that are colorcoded based on the flags (red for danger, green for safety). Thanks to this, even in cases where many pieces of information are concentrated in certain areas, different types of submitted information can easily be distinguished. Further, taking into account the accuracy of acquisition of GPS location information of mobile information terminals, the radius of the circles was set at $50 \mathrm{~m}$.

\section{6) Function for checking facilities that provide support} during disasters

In the present study, seven types of facilities included in the Tokyo Metropolitan disaster prevention maps ${ }^{(2)}$ are designated as facilities that provide support during disasters. They are temporary stay facilities, shelters, evacuation areas, water supply points, medical institutions, stations for aiding return to home (shops, etc. that provide support when people for whom it is difficult to return home are returning home on foot), and gas stands. Further, a system has been designed which enables users to check facilities that provide support during disasters in an optional range based on present location or any location, and based on any facility category. The facility names, categories, and addresses of the facilities that provide support during disasters are published, but the distance between two points cannot be calculated based on addresses. Therefore geocoding is conducted, addresses are converted to latitude/longitude, and then that data is stored in the database in advance.

Therefore, the system has a design which allows the search range to be selected from the range of 50 to $500 \mathrm{~m}$, and facility categories to be selected from the seven categories mentioned above. When a request for a check of facilities that provide support during disasters is sent from an information terminal, in order to measure the distance between the designated point and disaster support facilities in the area of that point, the difference between the latitude/longitude that is sent from the information terminal and the latitude/longitude of each disaster support facility is used to calculate the distance between the designated point and each disaster support facility. Thus, facilities that are within a range designated by the user are confirmed, and further, facilities in a designated category are displayed on the digital map of the Web-GIS.

\section{SYSTEM DEVELOPMENT}

\section{A. System Front End}

In the present study, as is described in detail below, unique functions for users are operated, and support for utilization of disaster information is conducted.

\section{1) Disaster information submission and viewing functions}

When a user submits disaster information, they go to the submission page using "Post disaster information". On the submission page, they input "Title", "Image", "Main Text", "Location", and submit their information. Concerning input of location, when the PC interface is used, the user clicks the location on the map and location information is added; however, when the interface for mobile information terminals is used, it is possible to add location information using a GPS. Concerning display of the time, as described in detail in Section V-B, for this system, the development of an operation system run by multiple administrators that is operated starting from normal times of no disaster is anticipated. If users move from a dangerous place to a safe one and then submit information, concerning submitted information that describes circumstances at a time in the past, administrators change the time display to match that time. Further, as described in Section IV-B, in both normal times and disaster outbreak times, users can submit information about dangerous or safe places and so on, communicate by commenting about information submitted by other users, and update submitted information in real time by adding to or amending the contents of all submitted information using comments.

When users log into the system, they can check the latest five items of submitted information on the initial page, and check submitted content and images on the disaster information list page. Further, as outlined in Section IV-B, users can view all submitted information on the digital map of the Web-GIS, and when using the PC interface for users, users can also view submitted information in detail using full-screen display. Further, as described in Section IV-B, all submitted 
information is automatically classified by the system and illustrated on the digital map in semitransparent circles divided into red for danger and green for safety, so users can easily distinguish between different types of information.

2) Function for viewing disaster information provided by governments

The overall degrees of danger (the degrees of danger calculated by combining the risk of building collapse and the risk of fire) published on the disaster prevention maps provided by Mitaka City and the Metropolis of Tokyo (the regions for operation of the system), and the seven types of disaster support facility described in Section IV-B were input into the GIS base map using Esri's ArcMap, and a disaster prevention map unique to the system of the present study was created. Through this, disaster information submitted by users who are local residents and disaster information provided by governments is all mashed up on the GIS base map, and users can check all this information on the one screen using the WebGIS.

3) Function for checking facilities which provide support in disaster outbreak times

Users can search for seven types of disaster support facility by setting their choice of range and facility category. Concerning search range, a radius of 50 to $500 \mathrm{~m}$ from a designated point can be selected from a pull-down menu. Facility category can be selected from among seven types, and disaster support facilities in the area of a present location or a location of the user's choice can be checked.

\section{4) Disaster information ranking function}

By viewing disaster information that has already been submitted and using the button function, users can easily indicate that they have the same information if that is the case. In addition, a ranking function has been added to the button function, so disaster information items for which the most amount of users have the same information are displayed in descending order on the disaster information ranking page of the user screen.

\section{B. System Back End}

\section{1) System for classifying submitted information}

When users submitted disaster information, the system classifies the submitted information. Before submitted information is stored in the database, matching using regular expressions with respect to character strings stored in PHP variables is performed. In the case when a character string which is a matching target matches when a preg_match function is used, a value returned by the function is obtained. In this case, 1 or 2 is assigned to the variable for a flag, and is stored in the database together with the submitted content. The character strings which are targets of matching are the words "danger" and "dangerous" for information relating to danger, and the word "safe" for information relating to safety. Concerning this point, misclassification due to fluctuation in expression is prevented by displaying submission examples on the initial page of the system in advance. Information classified as outlined above is updated when the web page is loaded, and is depicted on the digital map of the Web-GIS using colorcoded semitransparent circles.
2) System for management of submitted information by administrators

Every user's submissions of information and image files are all stored as data in the database of the system. Administrators manage users and check submitted information using a list screen designed especially for the purpose. Administrators can take the measure of suspending accounts of users who have made inappropriate transmissions or behaved inappropriately, and if by any chance an inappropriate submission is made, administrators can delete the submission with just one click. Thanks to these features, there is no need for administrators to search to see whether or not inappropriate submissions of information have been made within the system; therefore, their burden can be lessened.

Further, for this system, it is desirable to develop a system of operation in which starting from normal times of no disaster, there are multiple administrators, consisting of government employees, people in firefighting and police organizations, and local residents. In addition, it is desirable that in the system of operation, information submitted by local residents is routinely checked on a high-frequency basis, and the reliability and consistency of information can always be guaranteed by taking the measure of deleting inappropriate submissions of information should any be discovered, and checking that submitted information is being appropriately classified by the system for classifying submitted information mentioned in the previous section. When a disaster has broken out, it is necessary to take not only the measures outlined above, but also to update published submitted information in real time and always guarantee the reliability and consistency of the information by taking the following measures. When multiple pieces of submitted information contradict each other, it is necessary to check the information by referring to information provided by other media and information systems, and then delete inappropriate information. Further, it is necessary to delete and amend information provided by local residents and governments in the case that it has become inappropriate in the circumstances of the disaster, which change by the minute.

\section{System Interfaces}

The system has three kinds of interface - a PC screen for users (Fig. 2), a mobile information terminal screen especially optimized for smartphones and tablet terminals (Fig.3), and a PC screen for administrators. Additionally, as examples of the PC pages for users, Fig. 4 shows the page for viewing submitted information, and Fig. 5 shows the page for checking facilities that provide support in disaster outbreak times. As mentioned earlier, they can communicate by commenting about information submitted by other users, and update submitted information in real time by adding to or amending the contents of all submitted information using comments on the former page. These pages are linked to the top page (Fig. 2), and this system has the similar pages to them optimized for mobile information terminals. Specifically for mobile information terminals, the pages for viewing submitted information and checking facilities that provide support during disasters are respectively shown on the middle and right parts in Fig. 3. 


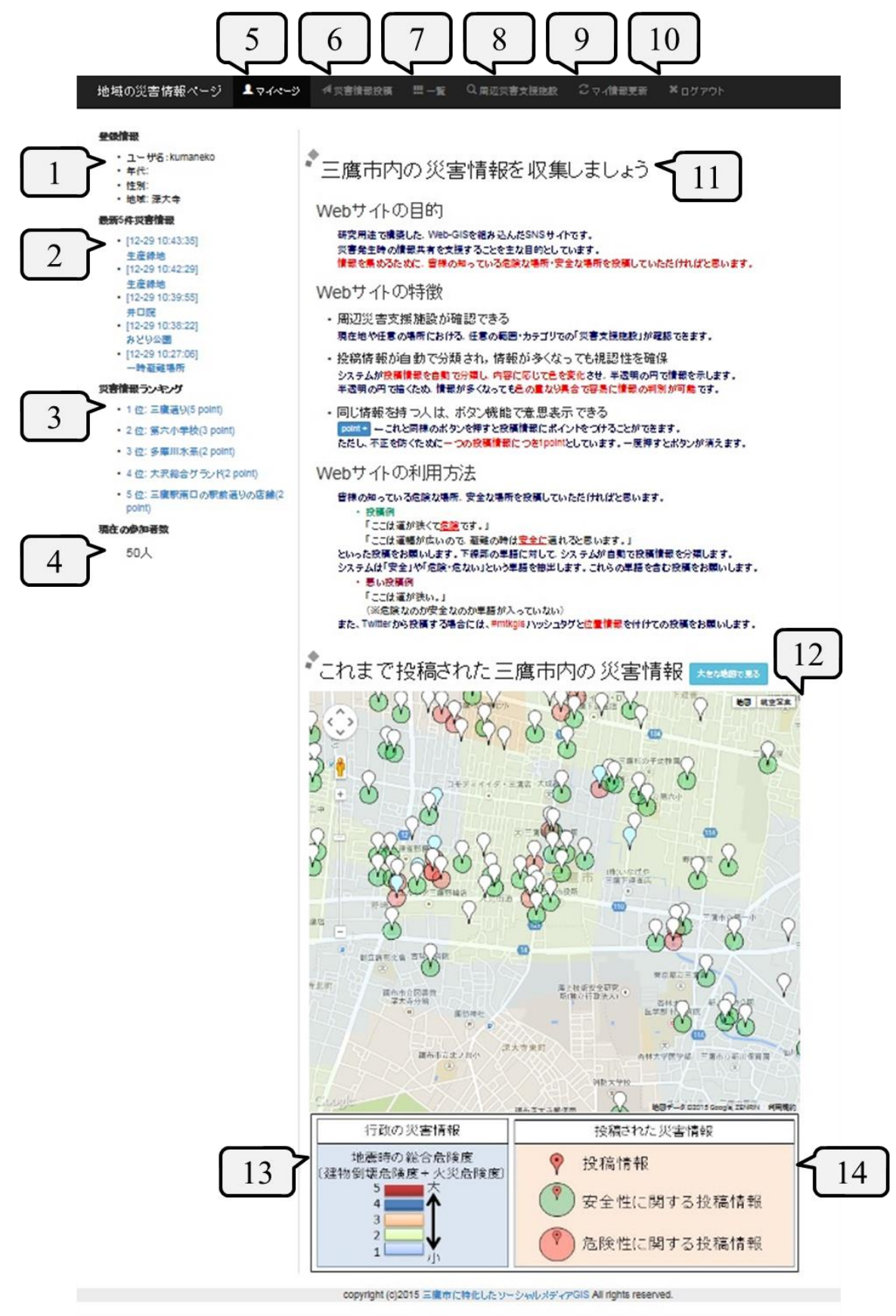

\begin{tabular}{|c|l|}
\hline \multicolumn{1}{|l|}{ No. } & Description \\
\hline $\mathbf{1}$ & User profile publication \\
\hline $\mathbf{2}$ & The five most recent items of submitted information \\
\hline $\mathbf{3}$ & The five most important items of submitted information \\
\hline $\mathbf{4}$ & The number of users \\
\hline $\mathbf{5}$ & Go to my page \\
\hline $\mathbf{6}$ & Go to the page where information can be submitted from computers \\
\hline $\mathbf{7}$ & List of submitted information \\
\hline $\mathbf{8}$ & Go to the page where support facilities in times of disaster can be checked \\
\hline $\mathbf{9}$ & Go to the page where change and registration of personal data can be made \\
\hline $\mathbf{1 0}$ & Logout \\
\hline $\mathbf{1 1}$ & Explanation to use this system \\
\hline $\mathbf{1 2}$ & Disaster information is displayed on Web-GIS digital map in the region of operation (Mitaka City) \\
\hline $\mathbf{1 3}$ & General degree of risk \\
\hline $\mathbf{1 4}$ & Explanation of disaster information submitted by users \\
\hline
\end{tabular}

Fig. 2. PC screen for users 


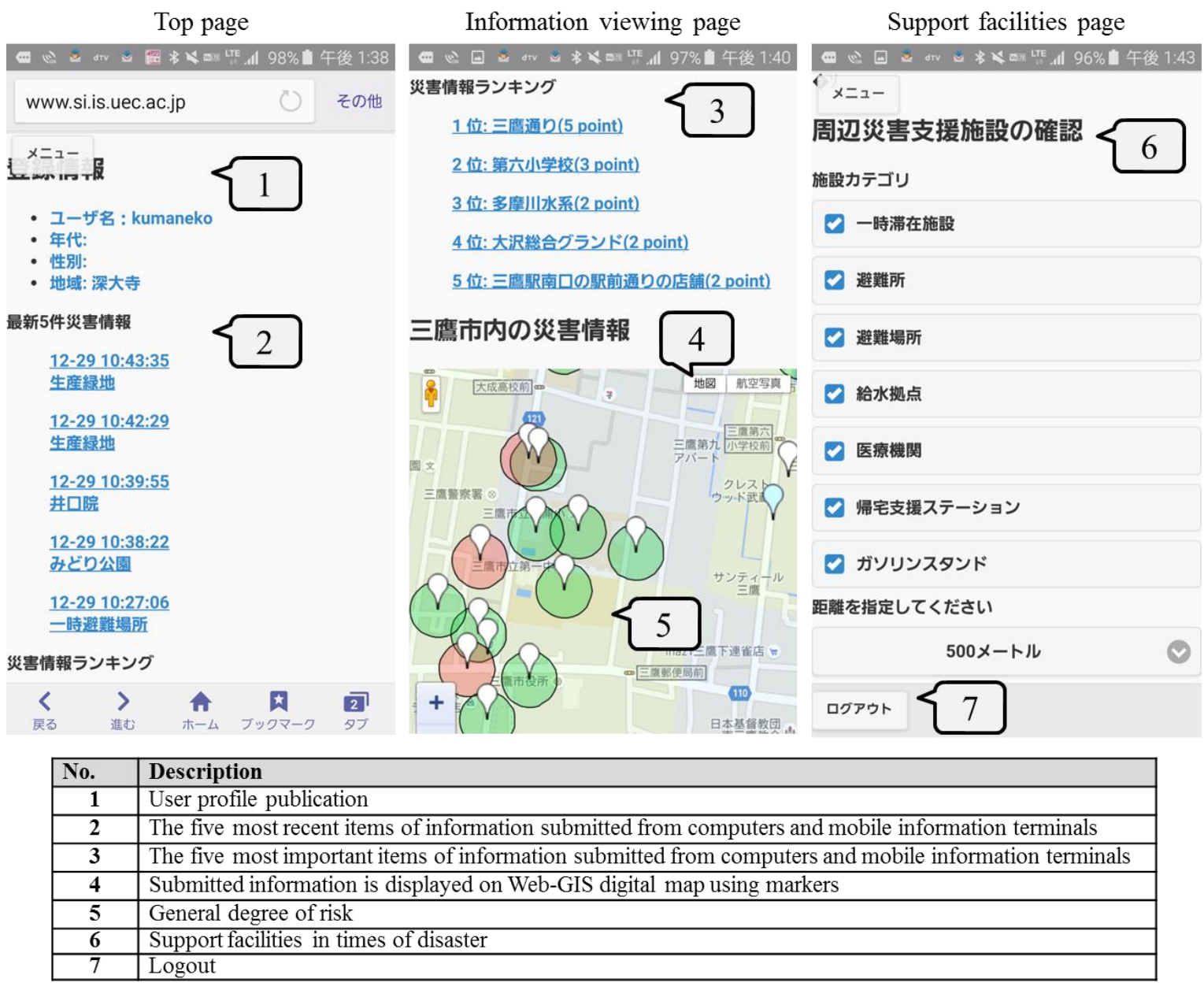

Fig. 3. Mobile information terminal screen screen for users

\section{TEST OPERATION AND OPERATION IN THE REGIONAL COMMUNITY}

In accordance with the operation process in TABLE I, test operation of the social media GIS designed and developed in the present study and evaluation of the test operation were conducted, and then full-scale operation was conducted.

\section{A. Comparison with Existing Services in Region for Operation of System}

In Mitaka City, the region for operation of the system, a plan for supporting the evacuation of people requiring special help during disasters was formulated in 2011, and a disaster prevention map ${ }^{(3)}$ has also been created and provided. TABLE II compares disaster prevention maps relating to Mitaka City with the features of the system of the present study. The Mitaka City disaster prevention map can be used to check locations of large-area evacuation sites designated by the city and the overall degree of danger of locations within the city (the degree of danger in Mitaka City is ranked using three levels only -1 to 3 ). However, since it is published in PDF format, information cannot be viewed all at once. The Tokyo Metropolitan disaster prevention maps are published as digital maps, so it is easy for users to view information they need, and the maps include the facilities that provide support during disasters that were mentioned in Section IV-B and other information. However, the maps do not have detailed disaster information concerning each region. Further, these government disaster prevention maps do not include any disaster information that is experience-based information possessed by local residents at all.

Therefore, the system of the present study is useful in that it can effectively provide detailed disaster information specific to the region where it is operated, by gathering and accumulating disaster information submitted using an SNS and twitter by users who are local residents and displaying the disaster information on the digital map of a Web-GIS. Further, it is useful in that disaster information provided by users who are local residents and by governments can all be checked visually on the digital map, useful in that the system automatically classifies submitted information and immediately displays it on the digital map, and can also handle situations during disasters when there is an information glut, and useful in that users can use the system to check facilities that provide support during disasters. Even in disaster outbreak times, if an environment in which communication can be conducted can be secured, disaster information can be gathered, accumulated, and provided by the system, in the same way it is during normal times. Therefore, the system can also supplement efforts made by governments concerning disasters. 


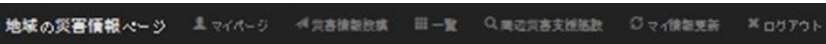

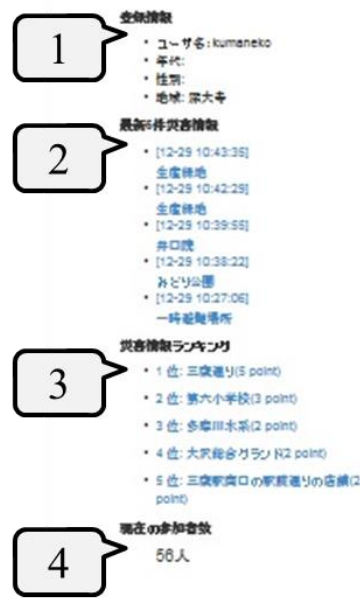

"下連雀3丁目の店舗間の道路 (1point)

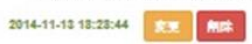

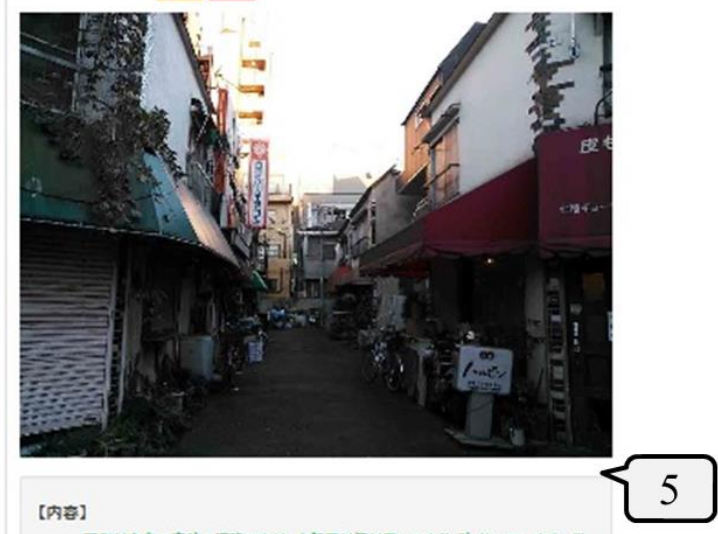

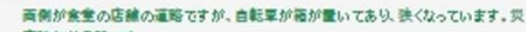

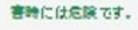
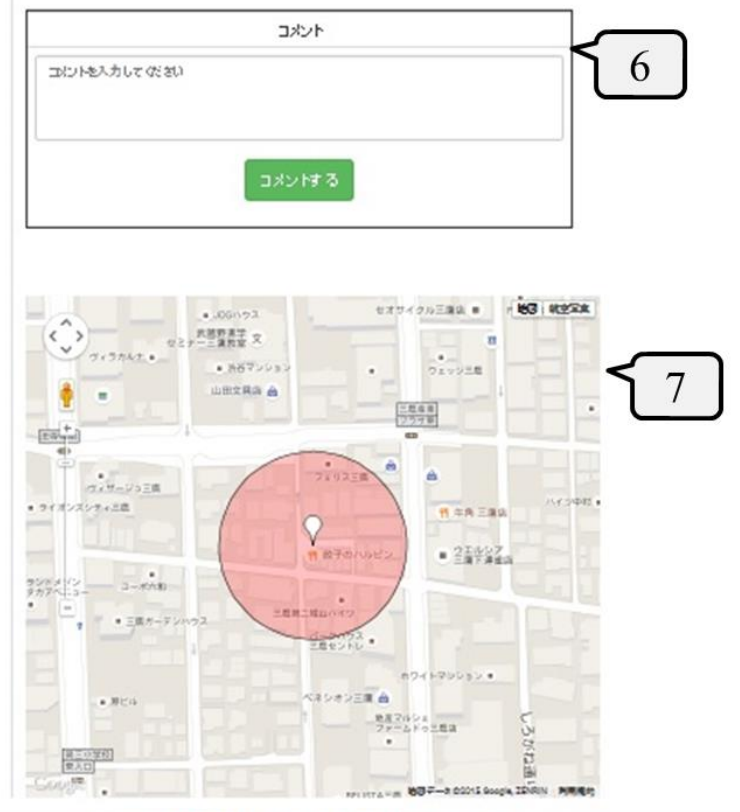

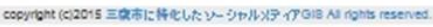

\begin{tabular}{|r|l|}
\hline No. & Description \\
\hline $\mathbf{1}$ & User profile publication \\
\hline $\mathbf{2}$ & The five most recent items of submitted information \\
\hline $\mathbf{3}$ & The five most important items of submitted information \\
\hline $\mathbf{4}$ & The number of users \\
\hline $\mathbf{5}$ & Submitted information and image \\
\hline $\mathbf{6}$ & Comment column \\
\hline $\mathbf{7}$ & Disaster information is displayed on Web-GIS digital map in the region of operation (Mitaka City) \\
\hline
\end{tabular}

Fig. 4. Page for viewing submitted information (PC screen) 


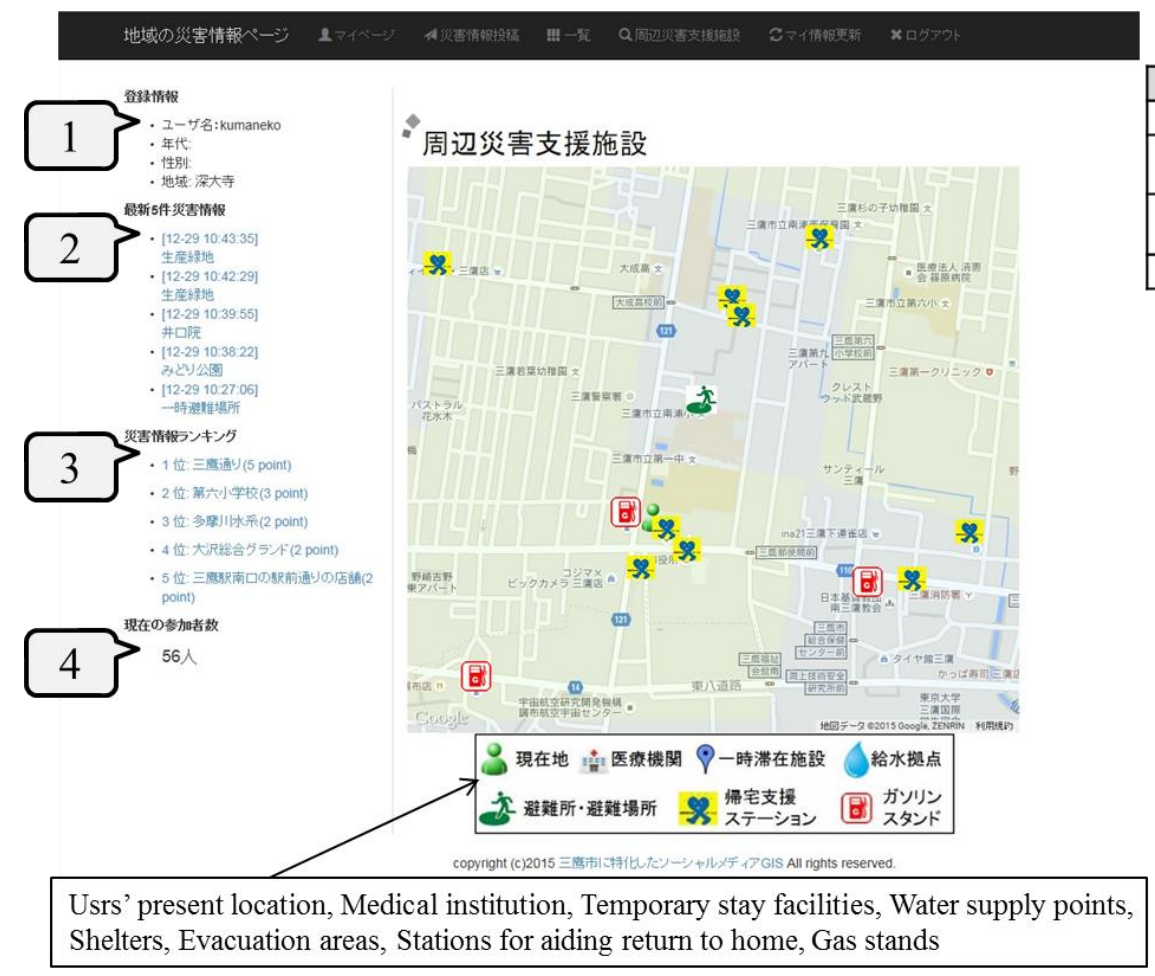

\begin{tabular}{|c|l|}
\hline No. & Description \\
\hline $\mathbf{1}$ & User profile publication \\
\hline $\mathbf{2}$ & $\begin{array}{l}\text { The five most recent items of submitted } \\
\text { information }\end{array}$ \\
\hline $\mathbf{3}$ & $\begin{array}{l}\text { The five most important items of submitted } \\
\text { information }\end{array}$ \\
\hline $\mathbf{4}$ & The number of users \\
\hline
\end{tabular}

Fig. 5. Page for checking facilities that provide support in disaster outbreak times (PC screen)

\section{B. Operation Test and Evaluation of Operation Test}

Before full-scale operation was conducted, three students in their twenties who were residing or attending school in Mitaka City were selected and a one-week operation test was conducted. After the operation test, the students who participated in the operation test were interviewed. In the interviews, the students expressed the opinion that a large-sized map was desirable when viewing disaster information on the digital map. Therefore, the system was redeveloped concerning this point only - the full-screen display for the PC interface for users, mentioned in Section IV-B.

\section{Operation}

When full-scale operation was conducted, local residents aged eighteen years or over residing in, commuting to, or attending school in Mitaka City were targeted as users. Pamphlets and operating instructions were placed in the city hall and bases of citizen activities in order to appeal for use of the system. When first using the system, users registered the personal information items of "User name", "Password", "Age group", "Gender", "Region", and "Email address". Concerning "Age group", "Gender", and "Region", which were displayed on the screen, users could set whether or not to make these items public at their discretion. After registering, users could use the system when they logged in, and after logging in, users could reset the above-mentioned items of personal information that they had registered.

\section{EVALUATION}

In this section, according to the operation process shown in TABLE I, firstly based on results of access analysis utilizing log data, and analysis of submitted information from during full-scale operation, an evaluation of operation concerning the aim of the system - that is, the aim of supporting utilization of disaster information in order to reduce the effects of natural disasters from normal times through to disaster outbreak times - was conducted. Next, based on the results of these evaluations, measures of using the system even more effectively were identified.

\section{A. Access count and means of access}

\section{1) Outline of access analysis}

In order to analyze user trends, analysis was performed using access logs collected during the period of operation. In the present study, Google Analytics was used for collecting log data. Google Analytics is an access analysis service provided free of charge by Google, and is widely used. It can be used by setting up a tracking code in the source of a web page.

\section{2) Results of access analysis}

The total access count for the period of operation was 2,537. Although there were differences in the access counts for each week, the average weekly access count was approximately 254 , and it can be said that users used the system on a continual basis. Concerning the access counts for each page, the access count for the submission page was the highest, being 34\% of the total. Next was the access count for the page for checking facilities which provide support during disasters (10\%), followed by the access count for the viewing page (9\%). It can be seen that even if users did not submit information, many users checked disaster support facilities and viewed disaster information. Concerning means of accessing the pages, $95 \%$ of access was from PCs and 5\% was from mobile information terminals; therefore, it can be presumed that use was mainly from PCs, and mobile information terminals were used as a supplementary means of access. However, the fact that mobile 
information terminals were also used shows that it is possible that the system can mitigate spatial and temporal restrictions during both normal times and disaster outbreak times.

\section{B. Features of submitted information}

Fig. 6 shows changes in the total number of users and the total number of submissions of information from week to week during the period of operation. Both the number of users and the number of submissions of information gradually increased, although there are differences in the rate of increase from week to week. The total number of submissions of information was 260 (the weekly average is approximately 26). Submissions from Twitter were all made using mobile information terminals, but there were only six submissions from Twitter. Of the total number of submissions, $81 \%$ included images, and $4 \%$ of submissions were commented on. The fact that the comment function was also used and users were able to communicate with each other indicates that it can be anticipated that this function will be used not only in normal times but also in disaster outbreak times. Information concerning danger made up $20 \%$ of the total, information concerning safety made up $68 \%$, and other types of information made up $12 \%$, and concerned disaster prevention storehouses, water supply points, and water wells for earthquake disasters.

TABLE I. OPERATION PROCESS OF THE SYSTEM

\begin{tabular}{|c|c|c|c|}
\hline Process & Aim & Period & Specific details \\
\hline $\begin{array}{l}\text { 1. Survey of } \\
\text { present } \\
\text { conditions }\end{array}$ & $\begin{array}{l}\text { To understand efforts related to tourism in the } \\
\text { region for operation (Mitaka City) }\end{array}$ & July 2014 & $\begin{array}{l}\text { - Survey of government measures and internet services } \\
\text { - Interviews with government departments responsible, etc. }\end{array}$ \\
\hline $\begin{array}{l}\text { 2. System } \\
\text { configuration }\end{array}$ & $\begin{array}{l}\text { Configure the system in detail to suit the region } \\
\text { for operation }\end{array}$ & $\begin{array}{l}\text { August } \\
2014\end{array}$ & $\begin{array}{l}\text { - Define system requirements } \\
\text { - System configuration } \\
\text { - Create operation system }\end{array}$ \\
\hline 3. Operation test & Conduct the system operation test & $\begin{array}{l}\text { September } \\
2014\end{array}$ & $\begin{array}{l}\text { - Create and distribute pamphlets and operating instructions } \\
\text { - System operation test }\end{array}$ \\
\hline $\begin{array}{l}\text { 4. Evaluation of } \\
\text { operation test }\end{array}$ & $\begin{array}{l}\text { Reconfigure the system based on results of } \\
\text { interviews with operation test participants }\end{array}$ & $\begin{array}{l}\text { October } \\
2014\end{array}$ & $\begin{array}{l}\text { - Evaluation using interviews } \\
\text { - System reconfiguration } \\
\text { - Amendment of pamphlets and operating instructions }\end{array}$ \\
\hline 5. Operation & Conduct actual operation of the system & $\begin{array}{l}\text { October- } \\
\text { December } \\
2014\end{array}$ & $\begin{array}{l}\text { - Appeal for use of the system } \\
\text { - Distribution of pamphlets and operating instructions } \\
\text { - System operation management }\end{array}$ \\
\hline 6. Evaluation & $\begin{array}{l}\text { Evaluate the system based on the results of access } \\
\text { analysis which used log data during the period of } \\
\text { actual operation, and the results of analysis of } \\
\text { submitted information }\end{array}$ & $\begin{array}{l}\text { January } \\
2015\end{array}$ & $\begin{array}{l}\text { - Evaluation using access analysis which used log data, and } \\
\text { analysis of submitted information } \\
\text { - Identification of measures for using the system even more } \\
\text { effectively }\end{array}$ \\
\hline
\end{tabular}

TABLE II. COMPARISON OF FEATURES WITH DISASTER PREVENTION MAP RELATED TO REGION FOR OPERATION

\begin{tabular}{|c|c|c|c|c|}
\hline & Use of digital map & Viewing means & $\begin{array}{l}\text { Submitted information from local } \\
\text { residents }\end{array}$ & $\begin{array}{l}\text { Automatic classification of } \\
\text { submitted information }\end{array}$ \\
\hline $\begin{array}{l}\text { Tokyo Metropolitan disaster } \\
\text { prevention maps }\end{array}$ & Yes & Digital map & No & No \\
\hline Mitaka disaster prevention maps & No & PDF & No & No \\
\hline The system of the present study & Yes & Digital map & Yes & Yes \\
\hline
\end{tabular}

Further, as shown by Fig. 7, submissions of information are dispersed over the whole area of Mitaka City, so it can be assumed that the locations of users' places of residence, commutation destinations, and schools were not concentrated in limited areas. However, there are regions where the amount of submissions of information is somewhat concentrated. In particular, there were many submissions of information concerning the area of the train station. This is considered to be due to the fact that many people come and go through this kind of area daily, and there are many places where narrow streets become even narrower due to bicycles, luggage, and the like. 


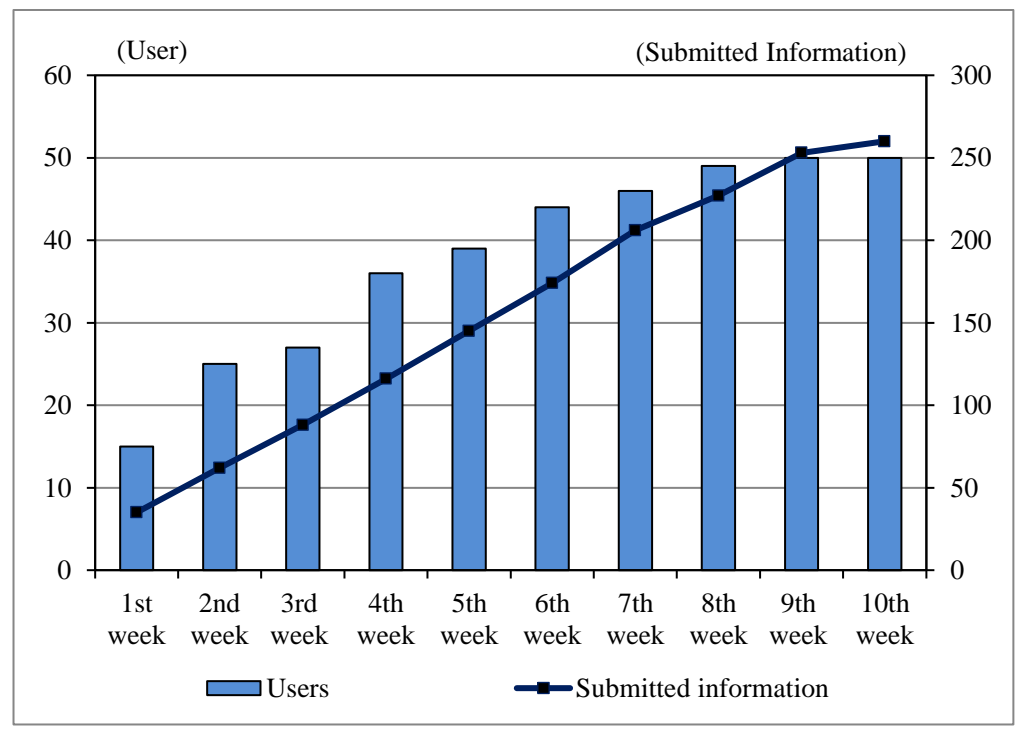

Fig. 6. Changes in the total number of users and the total number of submissions of information during the operation period

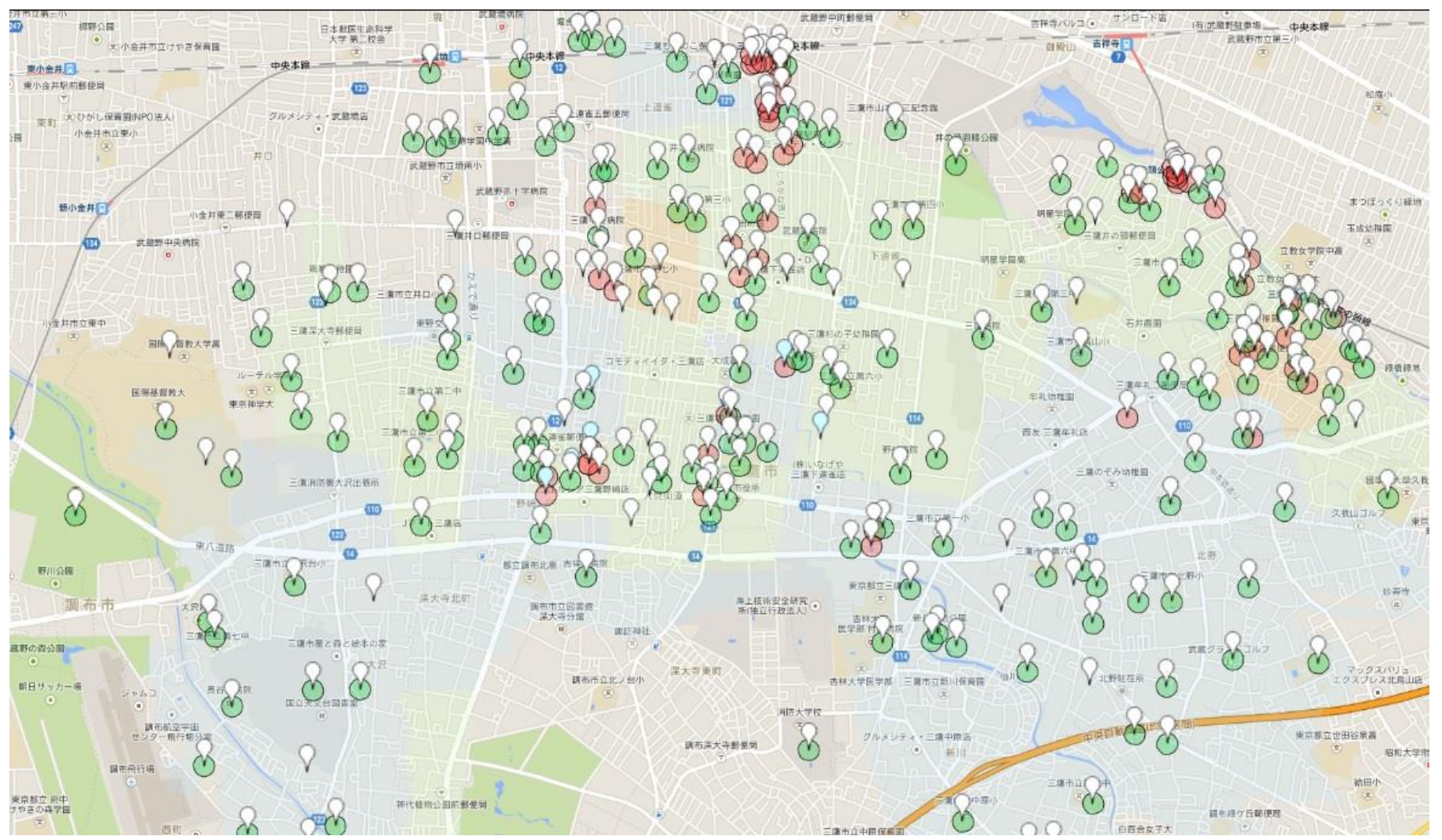

Fig. 7. Distribution of submitted information in the region for operation of the system (Mitaka City)

\section{Identification of Measures for Using the System}

Based on the results of the evaluation of the operation in this section, measures for using the system even more effectively were summarized into the two points below.

1) Notification of information to passive users

GPS information of users' information terminals is continually obtained at a set interval, and the system searches for disaster information in the vicinity of the user and pushnotifies the user of information within a set range in the vicinity of the user. Through this, passive users are notified of information.

\section{2) Operation of the system using cloud computing}

In order to be sure the system operates even during disaster outbreaks, the system is distributed in earthquake-proof data centers. Doing this allows more reliable operation of the system than server operation by individuals. Further, combining ArcGIS Online (which is provided by Esri) with the 
system when it is used allows all servers to be operated using cloud computing.

\section{CONCLUSION AND FUTURE RESEARCH TOPICS}

The conclusion of the present study can be summarized into the following three points:

1) A social media GIS which integrated a Web-GIS, an SNS and Twitter and which included a function for classifying submitted information was designed and developed. A system which supports utilization of information in order to reduce the effects of natural disasters which anticipates use not only in normal times but also use during disasters when there is an information glut was proposed. The system supports utilization of information by depicting submitted information based on location information and content using color-coded semitransparent circles, and by displaying information based on information about present location. Mitaka City in the Metropolis of Tokyo was selected as the region for operation of the system. After a survey of existing conditions was conducted, the system was developed in detail.

2) Since full-scale operation was to be conducted for ten weeks, a one-week operation test was conducted in advance and an area for improvement of the system was identified. After that, the system was reconfigured. People targeted as users of the system were those residing in, commuting to, or attending school in Mitaka City aged eighteen years of age or over. The number of users was fifty in total. Users in their forties and fifties made up the greatest proportion of users, at $32 \%$ and $30 \%$, respectively, while the proportion of users in their twenties, thirties, and sixties and above was 14\%, 12\%, and $10 \%$, respectively, so the system was used by a wide range of age groups. During the period of operation, users accessed the system from PCs and mobile information terminals, and submitted and viewed information.

3) An evaluation of the operation was conducted based on access $\log$ analysis and submitted information. The former showed that the system was continually accessed throughout the period of operation, and the later showed that 260 pieces of disaster information were submitted, dispersed throughout Mitaka City. Based on the results of the evaluation of the operation, measures for using the system even more effectively were summarized into the following two points: (1) Notification of information to passive users, and Operation of the system using cloud computing.

Future topics for research include expanding the stages of use of the system to times of post-disaster restoration and redevelopment, cooperating with firefighters and police, and operating the system with the participation of a wider user base, and increasing the track record of use of the system by operating it in other regions as well, and further increasing the significance of using the social media GIS developed in the present study.

\section{ACKNOWLEDGEMENTS}

In the operation of the social media GIS, enormous cooperation was received from those in Mitaka City of Tokyo metropolis and the neighboring area in Japan. We would like to take this opportunity to gratefully acknowledge them.

\section{NOTES}

1) Japanese Ministry of Land, Infrastructure, Transport and Tourism's Hazard Map Portal Site: http://disapotal.gsi.go.jp/. (Accessed 2014, August 20). (Website)

2) Tokyo Metropolitan disaster prevention maps: http://map.bousai.metro.tokyo.jp/. (Accessed 2014, August 20). (Website)

3) Mitaka City disaster prevention map: http://www.city.mitaka.tokyo.jp/c_service/003/003310.html. (Accessed 2014, August 20). (Website)

\section{REFERENCES}

[1] Cabinet Office, Government of Japan, "White paper on disaster management 2012", Tokyo, 2012.

[2] Regional Research Committee, Science Council of Japan, "Recommendations: towards the accumulation and utilization of Regional Knowledge", Tokyo, 2008.

[3] Central Disaster Management Council, "Committee for policy planning on disaster management - Final report: Toward reconstruction for a Japan that is unshakable", Tokyo, 2012.

[4] R. W. Greene, "Confronting catastrophe: A GIS handbook", ESRI Press, Redlands, 2002.

[5] A. S. Vivacqua and M. R. S. Borges, “Taking advantage of collective knowledge in emergency response systems", Journal of Network and Computer Applications, Vol.35, No.1, pp.189-198, 2012.

[6] A. Mansouriana, A. Rajabifardb, M. J. Valadan Zoej, and I. Williamson, "Using SDI and web-based system to facilitate disaster management", Computers and GeoSciences, Vol.32, No.3, pp.303-315, 2006.

[7] J. M. M. Neuvel, H. J. Scholten and A. van den Brink, "From spatial data to synchronized actions: The network-centric organization of spatial decision support for risk and emergency management”, Applied Spatial Analysis and Policy, Vol.5, pp.51-72, 2012.

[8] Cabinet Office, Government of Japan, "White paper on disaster management 2012", Tokyo, 2012.

[9] M. Murakami, A. Shibayama, Y. Hisada, T. Ichii, S. Zama and M. Endo, "Development of an information gathering and sharing system that supports disaster prevention activities carried out by local residents and local governments", Journal of Japan Association for Earth Engineering, Vol.9, No.2, pp.200-220, 2009.

[10] T. Okuma and K.Yamamoto, "Study on Social Media GIS for accumulating urban disaster information: Accumulation of disaster information during normal times for purposes of disaster reduction measures", Socio-Informatics, Vol.2, No.2, pp.49-65, 2013.

[11] T. Murakoshi and K. Yamamoto, "Study on Social Media GIS for supporting utilization of disaster information: For disaster reduction measures in normal times through to times of disaster outbreak", SocioInformatics, Vol.3, No.2, pp.17-31, 2014.

[12] T. Yamanaka, Y. Tanaka, Y. Hijikata and S. Nishida, "A supporting system for situation assessment using text data with spatio-temporal information", Japan Society for Fuzzy Theory and Intelligent Informatics, Vol.22, No.6, pp.691-706, 2010.

[13] K. Moriya, S. Sasaki and Y. Kiyoki, "A dynamic creation method of environmental situation maps using text data information", DEIM Forum 2009, pp.B1-6, 2009.

[14] S. Honjo and H. Yuhashi, "Information society for disaster reduction Great East Earthquake and mobile communication-“, NTT Publishing Co., Ltd., Tokyo, 2013.

[15] H. Ikemi, T. Esaki and Y. Mitani, "Sustainable data-sharing for disasters based on the Wiki and GIS technologies", Theory and Application of GIS, Vol.17, No.1, pp.93-99, 2009. 
[16] S. Okano, S. Yasui, K. Okazawa, H. Ebara and H. Okada, "Hybrid disaster information distribution method for community networks", IEICE Technical Report, IN, Information Network, Vol.108(458), pp.499-504, 2009.

[17] T. Kato, M. Kobayashi, N. Sato and T. Yotsuyanagi, "Towards implementing a disaster management information mashup Ssystem in the community", Monthly Journal of the Institute of Industrial Science, University of Tokyo, Vol.62, No.4, pp.377-380, 2010.

[18] T. Takatani, T. Iwaki and Y. Kato, "Creation of a regional disaster prevention support system aimed at planning urban areas that are resistant to natural disasters", Bulletin of Mizuru National College of Technology, No.43, pp.34-50, 2008.

[19] M. Inoguchi, K. Tamura, T. Furuya, R. Kimura and H. Hayashi, "Proposal aimed at realization ofeffective on-site spatial information mashup for emergency map creation teams: A case study of the 2011 Great East Japan Earthquake", Journal of Social Safety Science, No.15, pp.219-229, 2011.

[20] A. Kawasaki and K. Meguro, "New trends in disaster response support using web mapping, observed in the 2010 Haiti Earthquake", Monthly Journal of the Institute of Industrial Science, University of Tokyo, Vol.62, No.4, pp.409-416, 2010.

[21] K. Yamamori, "Establishment of a bulletin board for times of disaster", Bulletin of Faculty of Education Mie University, No.61, pp.13-19, 2010.
[22] K. Korida, T. Kikuchi, N. Yoshiyama, Y. Shibata, M. Takahashi, M. Takenaka and E. Aoki, "Development of community disaster prevention SNS based on the trust and relationships between local inhabitant", The Special Interest Group Technical Reports of Information Processing Society of Japan, CSEC, "Computer Security", 2011-CSEC-52(16), pp.1-6, 2011.

[23] H. Wasaki, "Disaster and regional SNS: The connection effect for rescue/recovery that came to light through the Sayou Town Torrential Rain Disaster", Bulletin of the National Museum of Ethnology, No.106, pp.127-146, 2012.

[24] M. Yamamoto, H. Ogasawara, I. Suzuki and M. Furukawa, "Information dissemination network on Twitter during the Great East Japan Earthquake", Information Processing Society of Japan Magazine, Vol.53, No.11, pp.1184-1191, 2012.

[25] N. Yoshimura and T. Inoue, "Analysis of use of public institution accounts in the microblog service Twitter before, during, and after the Great East Japan Earthquake", The Special Interest Group Technical Reports of Information Processing Society of Japan, GN, "Groupware and Network Service", 2012-GN-83(5), pp.1-8, 2012.

[26] T. Yanagisawa and K. Yamamoto, "Study on information-sharing GIS for accumulating local knowledge in local communities", Theory and Applications of GIS, Vol.20, No.1, pp.61-70, 2012. 